\title{
Service industries and construction: trends and view at a quality assessment
}

\author{
Vladimir Okrepilov ${ }^{1}$, Svetlana Kuzmina ${ }^{2, *}$, and Tatiana Lebedeva ${ }^{2}$ \\ ${ }^{1}$ Institute for Problems of Regional Economics RAS \\ ${ }^{2}$ Peter the Great St.Petersburg Polytechnic University, Polytechnicheskaya, 29, St. Petersburg, \\ 195251, Russia
}

\begin{abstract}
This paper looks at the current issues of raising the quality of work in businesses of the service sector including to construction and transport. Options for classifying businesses of this sector are given, as well as a classification by the author. The peculiarities of work in these businesses are examined, along with the peculiarities of their work in the Northwestern District. The advantages of introducing quality management systems into these businesses are given. Furthermore, the interpretation of quality management principles as applied to the service industries and construction are looked at.
\end{abstract}

\section{Introduction}

Over the entire history of human civilization, the competitive advantages of a country have constantly been changing. Whereas in the beginning such advantages lay in the size of territory and presence of natural resources, later on, the main competitive advantage became industrial development and transport. However, in the postindustrial era, changes have yet again taken place, and the advantage of today is a high quality of life.

As is well known, the quality of life depends on a number of factors, including the development of the service sector especially in construction and transport. This sector is predominant, especially in major cities. Businesses of this sector influence the quality of life not only with the quality of the services provided, but also by their very existence, since the well-being of a great number of citizens depends on their condition and sustainability of work. Therefore, the issues of raising the quality of work in businesses are relevant. Moreover, some types of services, e.g., hospitality and tourism, directly impact the international image of our country, meaning that they can change its influence on the international stage.

\section{Research methodology and statistics}

The conducted research shows that the tendencies of growth in the service sector both in Russia and in the "Northwestern" macro-region correspond to the economic growth

\footnotetext{
*Corresponding author: kuzmina2003@bk.ru
} 
tendencies of developed countries. For example, in the countries of the EU and in the USA, $74 \%$ and $81 \%$ of all work-eligible citizens are employed in the service sector; in Japan it is $71 \%$. For comparison, in Kyrgyzstan, $48 \%$ work in the service sector, while in Tajikistan the number is only $27 \%$. In Russia, this figure, equals $65 \%$ [1].

Beginning in 2005, a steady growth of money turnover has been noticed in the service sector. Currently, $41.4 \%$ of the GDP is created in the trade and service sector, while in a megapolis like Saint Petersburg, the service sector makes up around 70\% of the GRP (This is comparable to large European cities (Moscow - 75\%, Amsterdam - 71\%, Hamburg $83 \%$, Madrid - 66\%)[2].

Based on its volume, the service sector of the Northwestern District places third after the Central and Volga federal districts. Its turnover equals $10.7 \%$ of total volume turnover. The turnover for the service sector of the Central federal district equals 33,7\%[3].

In view of the amplitude and variety of businesses in this sector, the issue of their classification is greatly relevant. Agencies of the national statistics recognize 10 sections of the service sector:

- Housing and communal, construction services;

- Transport services;

- Communication services;

- Domestic services;

- Healthcare services;

- Education system services;

- Hospitality and tourism services;

- Cultural services, as well as physical education and sport;

- Legal services;

- Social services for the disabled and the elderly;

- Other services.

Whereby the largest volume falls on the housing and communal services.

Another classification exists, which is based on the role the services have in the process of reproduction and the nature of needs which are met. Thus, the following are differentiated:

- service sector for material production (transport, construction, communication, domestic services),

service sector for personal growth (education, physical education, science, art),

service sector in the social sphere (trade, housing and communal services, healthcare).

Within the service sector, market and non-market services are also distinguished. Market services include services which are rendered on the market at economically significant prices: transport and construction services, trade, paid services at institutions of culture and education, healthcare, domestic services, financial intermediation services, and so on. In this case, it is not about the commercial type of the business. Among the nonmarket services can be found services offered free of charge or at prices of no economic significance: government services for people, free education, healthcare, etc. Here, it is about noncommercial businesses.

Furthermore, a mixed type of business exists where noncommercial businesses provide market services and the acquired profit goes towards their own growth.

Businesses of the service sector can be divided according to their form of ownership in the following way:

- government of federal subject;

- government of regional subject;

- municipal;

- private. 
During the course of the studies conducted, it was established that the businesses can also be classified according to a person's needs which they satisfy. Taking into account the various forms of ownership, the following classification, presented in table 1, is proposed.

An analysis of the development tendencies of the service sector in the Northwestern District shows that the push for its development was largely caused by negative tendencies, particularly, with the fall of industrial production and the reduction in the number of businesses [4]. In such conditions, the development of small businesses and individual entrepreneurship in the service sector contributed to the employment of citizens and the reduction in socio-economic tensions.

Currently, the service sector in this region is observing a disparity in development, which is connected to, above all, the presence or lack of effective demand for services. In other words, two types of development of the service sector can be distinguished. One of these is characterized by the preferential development of the so-called tertiary sector (finance, mass media, informatics). This type is characteristic exclusively for major cities, especially Saint Petersburg. The second type is characterized by the exclusive development of small trade and various domestic services. This type is more widespread in the Northwestern District.

A variation of the second type is the development of the service sector in small cities of Northern Europe, which are concerned with the mining of various subsoil assets or other raw materials. Here, the service sector, transport services, and support services to construction are developing.

An analysis of the condition of the normative framework shows that it is fairly well developed in the service sector. Thus, back in 2003, the national standard GOST R 521432003 was approved, in which the main types of social services were defined. Six forms of social services were included in the standard:

- social domestic;

- social medical;

- social psychological;

- social pedagogical;

- social economic;

- social legal.

Specific services for each type are enumerated in the standard. Quality requirements for all the social services listed are formulated in the standard GOST R 52142-2003.

A nomenclature for quality indicators in all means of passenger transport is established in GOST R 51004-96. Seven main indicators are included in the nomenclature, including safety and economy.

The most common of these types being: car services, hairdressing, and cosmetic servicesThe nomenclature of indicators is also determined according to:

- housing and communal services (GOST R 51617-2000, GOST R 51929-2002);

- tourist services (GOST R 51185-98);

- physical education and health improvement and sports services (GOST R 520242003, GOST R 52025-2003);

- household services (GOST R 51870-2002, GOST R 52059-2003, GOST R 524922005, GOST R 52113-2003) [5].

In this way, the national standards are still valid for some services and can serve as a basis for applying tools of quality economics, in particular, systems of quality management.

However, the application of tools of quality economics in the service sector is disproportionate. Whereas in some sectors, e.g. healthcare, education, financial services, systems of quality management are introduced on a wide scale and find popularity, in other sectors, such as in sports and fitness services and household services, they are still inadequately implemented. 
Table 1. Classification of businesses and institutions of the service sector.

\begin{tabular}{|c|c|c|c|c|c|c|c|c|c|c|c|c|c|c|}
\hline \multirow[b]{2}{*}{$\begin{array}{c}\text { Demands } \\
\text { Forms of } \\
\text { ownership }\end{array}$} & \multicolumn{2}{|c|}{ Health } & \multicolumn{3}{|c|}{$\begin{array}{l}\text { Comfortable } \\
\text { living conditions } \\
\text { and life activities }\end{array}$} & \multicolumn{2}{|c|}{ Leisure } & \multirow{2}{*}{ 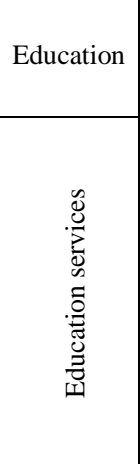 } & \multicolumn{3}{|c|}{ Movement } & \multicolumn{3}{|c|}{ Other } \\
\hline & 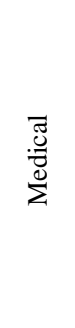 & 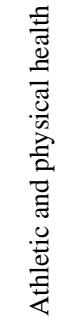 & 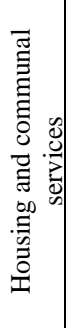 & 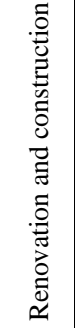 & 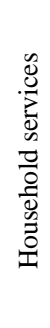 & 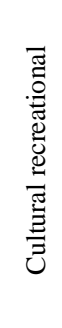 & 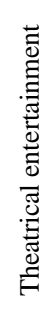 & & 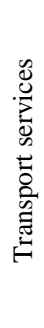 & 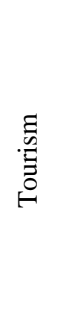 & 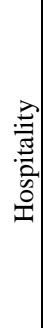 & 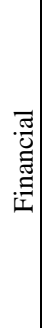 & 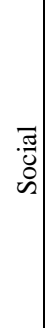 & $\begin{array}{l}\overline{\mathscr{g}} \\
\stackrel{0}{0} \\
\end{array}$ \\
\hline $\begin{array}{l}\text { Government } \\
\text { of federal } \\
\text { subject }\end{array}$ & 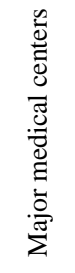 & & & & & 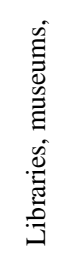 & 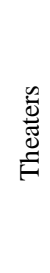 & 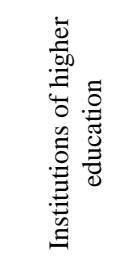 & 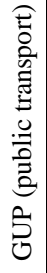 & & & & & \\
\hline $\begin{array}{l}\text { Government } \\
\text { of regional } \\
\text { subject }\end{array}$ & 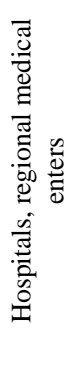 & 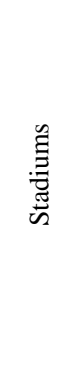 & & & & 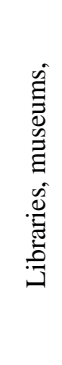 & 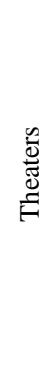 & 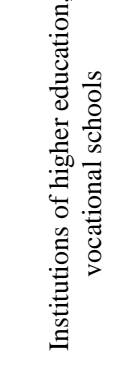 & & & & & & \\
\hline $\begin{array}{l}\text { Municipal } \\
\text { subject }\end{array}$ & & 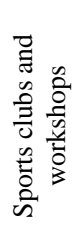 & $\stackrel{\text { 岁 }}{\Sigma}$ & & & 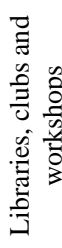 & & & & & & & 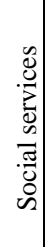 & \\
\hline $\begin{array}{c}\text { Private } \\
\text { (commercial) }\end{array}$ & 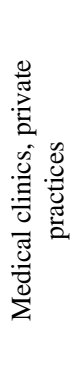 & 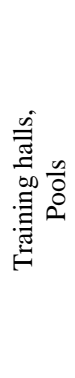 & 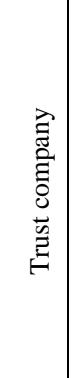 & 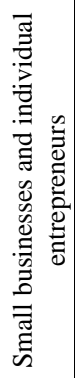 & 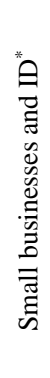 & 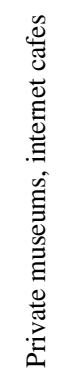 & 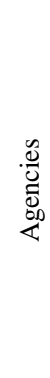 & 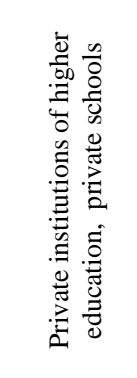 & 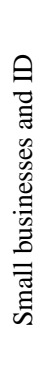 & 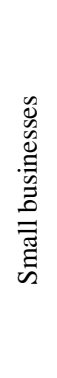 & $\begin{array}{l}\frac{n}{0} \\
\frac{0}{0} \\
0\end{array}$ & 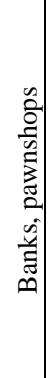 & & 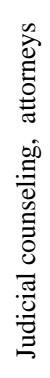 \\
\hline
\end{tabular}

In order to study the problem, all businesses of this sector were divided into two groups. 1 group - government and municipal 
State ownership is characteristic for the businesses of this group. As such, the services they offer can be best assigned to the category of state services. Consequently, the principles and approaches used when increasing the efficiency of government bodies (raising the quality of government services) can be fully applied to such businesses. The way to solve this problem is fairly well written about.

2 group - private commercial businesses

The main goal of such businesses is to increase profits. However, since they only have one source of profit, i.e., consumers of their services, an increase in profits is for the most part obtained by increasing the number of possible consumers, which, as it were, can only be achieved by constant quality improvement.

It can be said that the solution to the main issue of private commercial businesses lies in the observance of the main postulate of the modern approach to quality, i.e., that customer is king. This provides a foundation for implementing tools of quality economics in order to increase the efficacy of their operations and, consequently, to increase profits.

An analysis of experience managing in terms of quality in this sector shows that the application of quality management principles, in particular, facilitates the:

- achievement of a stably high quality of services with minimum costs;

- achievement of competitive services;

- increase in the level of customer satisfaction;

- improvement of company image;

- attraction of new consumers;

- involvement of employees in the process of increasing the quality of services provided.

\section{Results}

Along with this, the service sector especially construction and transport possesses a certain particularity that creates some difficulties when introducing quality management systems to these businesses.

1. A feature of the service is that the process of its production and consumption sometimes coincide. The quality of services can often only be assessed subjectively, based on the feelings of the consumer. In other words, quality assessment depends not only on the gender, age, education, and income level of the consumer, but also on their psychological and emotional state.

2. Services are not property of the consumer (unlike goods), the consumer simply has the right to access them.

3. The location of the business has great significance, as this is what initially determines the number of consumers.

4. During the production of services, it is necessary to not only go by traditional management based on subordination and division of labor, but also to use new approaches as well, such as working in teams with a common focus on not just the short-term result, but on long-term perspectives, cooperation, and partnership.

5. The use of services sometimes has a clearly defined seasonal or temporary nature. For example, the demand for renovation services to construction grows significantly in summer, while the demand for the transportation of passengers by public transport is especially great in mornings and evenings. The untimely satisfaction of growing needs leads to a reduction in the quality of services, thereby leading to a rise in the number of unsatisfied consumers.

Additionally, the specific peculiarities of the Northwestern District should be mentioned: 
1) The sharp imbalances in the development of the federal subjects of Russia, included in the Northwestern Federal District, as well as the substantial differences in their nature and climate.

2) The border position of a region and its vicinity to a country of the E.U., through which citizens of the district have international experience in evaluating the quality of services provided to them.

3) A certain monopoly in providing services, which is observed in areas of low population.

4) Price competition in terms of migrant workers.

5) A disparity in the development of the service sector in macroregions, causing unequal opportunities for companies and firms to access resources.

Furthermore, for large cities it is often impossible to objectively determine the number of consumer of any one service, including budgetary services, due to the high mobility of the population.

These circumstances are taken into account when developing the theory and practice of quality economics. In particular, a modified model of the quality management system is of interest. This model includes such points as determining the market segment and the quality of the services provided, as well as the concepts of service and company policy. In this case, the policy can be seen as a tool of information, serving to build relations between a company's management and the environment, specifically with resource suppliers, consumers (customers and clients), and its own employees.

\section{Discussions}

The specifics given for the activities of businesses of the service sector forces a certain adjustment to be made to the fundamental principles of quality management. In the opinion of the authors, they can be interpreted the following way.

Focus on the consumer. It is quite clear that the quality of life of clients who use the services of any one business should improve. In order for this to happen, there needs to be an understanding of people's current needs and inquiries along with an effort made to anticipate these needs, in other words, to foresee the emergence of any new demands.

In order to more effectively fulfill this requirement, there needs to be constant monitoring of the socio-economic situation in any given territory, as this allows the dynamics of effective demand to be predicted.

Applying this principle has the following benefits:

- the needs and demands of society become clearer and more understandable;

- the opportunity to adjust the goals and tasks of a specific business is provided, according to the changing needs and demands of society;

- the personnel of a business receive the information needed to more fully meet the needs of society.

Leadership. In order for a business to function effectively, the purpose and focus of the work need to be unified. This is achieved through:

- an adequate response to a change in the situation in a territory, an examination of the needs of interested parties;

a clear definition of development prospects and the strategy to reach them;

a clearcut definition of authority, responsibility, and accounting of the personnel and management;

- the adoption of various kinds of incentives for the personnel, personnel training;

- assisting the development of internal communications.

Applying this principle has the following benefits:

- a clear prediction of growth is determined;

- this prediction is presented in measurable goals and objectives; 
- the personnel of a business are involved in reaching these goals and objectives, they are interested and well informed.

Involvement of people. Applying this principle requires a business to use the experience and knowledge of its personnel. This needs to be achieved in order for the staff to:

- take on the responsibility of solving problems;

- actively search out opportunities for improvement;

- share their knowledge and experience freely;

- strive to be proactive and creative;

- receive personal satisfaction from their work.

Applying this principle has the following benefits:

- employees contribute to improving the work plans of the company and their execution; employees participate in determining the goals of the business;

employees participate in developing operational solutions and improving processes within the company;

- employees actively strive towards their own professional growth and development.

Process approach. Following this principle requires all aspects of a company's operation to be seen as processes. This is achieved by identifying the processes, their characteristics, input and output, and by establishing responsibility for overseeing the process (determining the "process manager"). When developing a process, it is necessary to take note of its stages, control measures, personnel training, equipment, methods, and materials necessary to achieve the desired result.

Applying this principle has the following benefits:

- more predictable work results, better use of resources, a decrease in the cost of work and the time needed to perform it;

- understanding the possibilities of a process allows the goals and tasks to be forecast;

conditions for preventing a significant number of mistakes are created;

the appearance of opportunities to develop staff training programs, coordinate the tasks of the company with staffing opportunities.

Improvement. This is one of the mandatory goals of development for every business. In order for this to happen, it is necessary to ensure that every employee contributes to the process, for which they need to be taught methods and tools for their continual improvement. Goals and measures for managing and overseeing improvement need to be defined and the obtained results assessed.

Applying this principle has the following benefits:

a method for continual improvement is used in strategic planning;

realistic goals for improvement and the resources for reaching them are outlined;

- the staff of an organization is involved in the continual improvement of its processes.

Making decisions based on evidence. The work efficiency of a business depends in large part on the available information and data analysis. Therefore, it is necessary to not only collect data and information relating to specific goals, but also to ensure their accuracy and reliability, analyze them using effective methods, and make decisions taking into account both the results of the analysis and the experience.

Applying this principle has the following benefits:

- more realistic and achievable plans are developed;

- the choice of purpose becomes more sound;

- the management of the improvement process becomes better;

- comments and suggestions "on the spot" become another source of information.

Management relations. Introducing the quality management principles to a company can benefit not only the consumers of services, but the suppliers of this business as well, since a reinforcement of input control encourages the supplier to raise the quality of their product. 
In order to do this, a special program needs to be developed within the company which would offer incentive measures to raise the quality of products and services[7].

Applying this principle has the following benefits:

- a partnership which is focused on continuous quality improvement being developed in a territory;

- encouraging suppliers allows the strategic goals of a company to be better defined;

- joint work leads to the work improvement of specific businesses as well as to overall quality improvement.

\section{Conclusions}

In conclusion, it is worth mentioning that in the new economy, quality, understood as the degree to which the demands and expectations of people are met, is becoming the main parameter when developing new types of goods and services, and one of the most important arguments in the growing competition. As the experience of advanced countries shows, the leading manufacturers are those who offer goods and services that satisfy the growing demands, i.e., products of a higher quality[8,9]. However, simply offering new products is not enough to secure an advantage in the modern economy. Its functioning and maintenance need to be guaranteed. In order to do this, quality control of work in all departments of a company is required, not only in its production or construction. Ensuring a high quality should fall on all of its employees[10]. Moreover, the problem of quality is so multi-sided and complex, that it is impossible to solve it at the level of a single business. It is necessary that businesses and their suppliers join forces and build partnerships. All of this allows the quality of services to be improved using a systematic approach, and consequently, reducing the risk of improper actions.

\section{References}

1. O.V. Kalinina, M.V. Lopatin, Actual Problems of Economics, 182, 8, 392-405 (2016)

2. I.I. Antonova, I.Z. Aronov, V.Y. Belobragin, O.V. Maksimova, Expertise 7(118), 2731 (2014)

3. P.I. Burak, T.I. Zvorykina, Standards and quality 5, 34-37 (2013)

4. S.A. Ayvazyan, V.S. Stepanov, M.I. Kozlova, Applied econometrics 2, 24 (2006)

5. V.V. Okrepilov, SPbPU Journal of Engineering Science and Technology, Economic sciences 1(187), 15 (2014)

6. G.N. Ivanova, S.N. Kuzmina, Economy of the Northwestern District: problems and prospects of development (State Center Test, St. Petersburg, 2015)

7. A. Evmenov, S. Kuzmina, V. Vlasova, MATEC Web of Conferences 170, 01033 (2018)

8. L. Svatovskaya, A. Sychova, M. Sychov, V. Okrepilov, MATEC Web of Conferences 53, 01024 (2016)

9. M.F. King, V.F. Renó, E.M.L.M. Novo, Social Indicators Research, 116, Issue 3, 681-698 (2014)

10. S. Abdallah, S. Thompson, N. Marks, Ecological Economics, 65, Issue 1, 35-47 (2008) 